\title{
Study on Common Errors and Countermeasures in English Translation
}

\author{
Qian Yao \\ Tianjin Maritime College Tianjin 300350
}

\section{Keywords: English translation; Common error; Countermeasures}

\begin{abstract}
Translation is showing the text meaning of one language with another language show, and English translation is the mutual conversion between Chinese and English in our daily use which means English translation is the main form of translation in China at present. This article comes from the perspective of English translation which focus on error and correct measures that often appear in the process of English translation, which is expected to enhance China's overall level of English in translation.

English translation is the main link in the process of learning English, and the improvement of English translation ability is crucial to the improvement of English proficiency. English translation ability is mainly reflected in listening, writing, speaking, reading and so on. In various types of English assessment tests in China, although the issues related to English translation are not many, but they are the key issues of high scores. Because of this, the improvement of English translation ability is not only able to improve English achievement, but also to improve the overall level of English.
\end{abstract}

\section{Common Way of English Translation}

Translation is a process of understanding and transforming the original text. The best effect of translation is not just the same literal meaning, but also in the emotional and background which are fitting the original. Master the commonly translation methods and common translation skills to improve the quality and efficiency of English translation has an indispensable role, and it can better restore the original intention. In the process of English translation, the general common in the following ways are as follows:

Literal Translation. Literal interpretation is the direct translation of the original text which is the most simple and direct method in English translation. The meaning of literal translation is to retain the original language emotion and original text in the process of English translation. Only from the language aspect, there are many similarities between Chinese and English, because of this, many English translation can use literal translation, and this approach can not only retain the original frame structure, but also can directly and accurately express the original meaning. This simple and direct English translation method can achieve accurate English translation goals reflecting the original containing the emotional and artistic conception. For example: literal translation of "lose face" is "shame" and literal translation of "paper tiger" means someone who looks fierce, while the essence is weakness. This translation not only expresses the meaning of the original text, but also retains the structure of the original text through the most simple and direct way to achieve the purpose of English translation.

Increased Translation. Increased translation is the most important work in the process of translation, because of the existence of text habits and different thinking modes between Chinese and English with the two language models, in the process of English translation will often need to add some content to achieve accurate performance of the original meaning. The increased translation can not only preserve the literal meaning of the original text, but also retain the hidden meaning and the image meaning of the original text. But in the process of the translation, to focus attention in the process of adding the translation of the content to the right and conforming to the original requirements which can make the readers in the reading process accurate understanding of the original text contained in meaning, which cannot abandon the original intention, and it also cannot be superfluous. Add the contents that should be appropriate with gaining is the right way of translation. The use of increased translation not only preserves the overall structure of the original 
text, but also can accurately show the meaning of the original text. For example: the meaning of "Once the trees falls, the monkeys on it will flee helter-skelter" is when the boss falls from power, his lackeys disappear, this way of translation not only express the original meaning, but also retains the original frame structure. The "helter-skelter" means flustered which is added to the original composition, although not the original words, but added the words can be that added to the emotional color making the translation more vivid.

Convert Parts of Speech. The translation method of converting parts of speech is also called lexical category conversion translation method, this translation refers to in the process of English translation, in order to fit the original language habits and expression patterns of vocabulary, grammar and sentence patterns in translation to make the translation changes, finally get the best translation effect, making readers understand and accept more easily in the process of reading. This way of translation method is actually the conversion of original part of speech and the original sentence in the composition, the original sentence pattern, the voice of the original and so on. For example: "Our University is co-adminis-trated by the School leaders and the Department of Education", this sentence is the original meaning of the school leaders and the leadership of the Department of education are leaders of our school, the process of translation of this sentence is the original conversion between noun and verb. "I 'm not for your opinion", this sentence translation process is the source of the preposition into verbs, the original meaning is that I do not fully agree with your proposal. The translation method of converting parts of speech not only can fit the meaning of the original text, but also can make the translation statement more vivid and explicit.

\section{Common Errors in English Translation}

In the process of English translation, the translation errors often occur due to the limitation of the original structure.

Wrong Understanding. "It's quite another story now", the right meaning of this sentence is "Now the situation is different", while with the effect of wrong understanding, it is translated into "Now the story is different".

"Every life has its roses and thorns", the right meaning of this sentence is "All people's lives are bitter and sweet", while with the effect of wrong understanding, it is translated into "All life has roses and thorns".

Use Error of Subject. "Shanghai have adopted a series of preferential policies to attract foreign capital", in the process of translation of this sentence, the right translation is "A series of preferential policies have been adopted in Shanghai to attract foreign capital", while in the above wrong translation, the subject is "Shanghai" where the "take" or "adopt" is regarded as predicate.

Errors of Punctuation and Compound Sentence. Cooperation with the United States is in line with Japan's interests. The right translation of this sentence is "Cooperation with the United States is in the interests of Japan".

Redundant Translation of Words. In the process of translation of "It is essential to strengthen the national defense", there often be errors of redundant translation of words, and translating it into "It is essential to strengthen the building of national defense" which is wrong.

Chinese Grammatical Mistakes. With the effect of Chinese grammatical mistakes, some translators translate the sentence "China used to be very backward in its economy" into "The Chinese economy used to be very backward".

\section{Countermeasures for Improving English Translation Ability}

For English translation is not a simple job, and in the English learning process, it will appear very objective factors affecting the quality of translation. Because of this, before the translation work, it is necessary to have a general understanding of the original text and understand the structure of the original grammar. Translation work should be taken with more cautious in case of error. 
Establish Correct Attitude. In the process of English translation, we should always remind ourselves that translation is a crucial science and should be strict and open-minded. In daily life, we also can pay more attention to the streets and buildings in English signs and billboards, thinking about the translation mistakes or not rigorous to continue to accumulate their own level of translation through the small details of life, remind ourselves of correct meaning of translation, and translation errors will not only make others cannot understand, or even cause irreparable loss. Translation work is not a trivial matter, which means before the translation work, it should first establish scientific and rigorous attitude.

Reasonable Arrangement of Translation Sequence. For English translation learning is not a short time, which is in need of long-term learning and accumulation. English translation can start from a simple article, from easy to difficult to help ourselves to establish interest in English translation, enhance our enthusiasm for English translation work and self-confidence. Only calm down can have the confidence and patience to treat English translation work.

Cultivate the Habit of Reading English Articles. For English articles reading is to expand the understanding of the main ways of English, which can develop our sense of English that effectively improve the understanding of English sentences. Through the reading of English articles, we can have a general understanding of the use of the article statement, understanding English grammar habits and thinking habits. "Chinglish" is the main reason for the emergence of Chinese and foreign languages because of the cultural differences and often reading English articles can effectively reduce the emergence of "chinglish". Read more articles in English can develop a good habit for English grammar, and English translation work will be more relaxed, which means the meaning will be more conforming to the original to ensure the accuracy of the translation that is very important to a good English reading habit to improve English translation ability.

Understand the Differences between English and Chinese. English sentence is the importance of combining between various words, generally speaking, in an English sentence, there is only one subject predicate structure, and if there are other means to express, it generally use non predicate verbs, conjunctions and clauses. Chinese is just the opposite, the Chinese sentence emphasis is the combination of the expression meaning, and Chinese sentences will not deliberately appear connection words with the logical relationship between sentences can be completed. In Chinese articles, it often appears in a sentence in a number of independent small sentences, there are multiple verbs, small sentences in the middle separated by commas. If we do not understand the grammatical differences between English and Chinese, we will not achieve the requirements of translation in the process of translation. In addition, in the process of English translation, if tense and voice are inconsistent with the subject predicate structure errors, we need to understand some knowledge of English grammar to translate higher quality articles.

\section{Conclusion}

For English translation is not only a kind of knowledge, but also an art, in order to improve the ability of English translation, we should be in peacetime learning and life to practice and focus on training. Although the current English translation faced with many problems, but as long as we face problems through our continuous efforts and improve, we will be able to continue to overcome these problems to improve the level of English translation, and translation is more conforming to the original translation to promote English translation work in China.

\section{References}

[1] Chunyuan Xiang. The causes and countermeasures of English translation errors in Lishui public signs [J].Journal of Lishui University, 2009, 03: 48-50.

[2] Bei Wu. Analysis on common error of business English translation [J].Journal of Yunnan University of Finance and Economics (Social Science Edition), 2009, 05: 155-156.

[3] Sujing Xie. Common errors and Countermeasures of College Students' English 
translation[J].Journal of Hubei Adult Education Institute, 2014,06:78-80.

[4] Qing Zhao. Analysis of common errors of translation in English for science and technology[J].Journal of Anshan University of Science and Technology,2003,06:478-480. 